International

Medical Society

http://imedicalsociety.org
Vol. 9 No. 67 doi: $10.3823 / 1938$

\section{Childhood Inactivity, a Public Health Priority

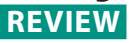

\section{Abstract}

The continuing epidemic of cardiovascular diseases calls for a renewed and intensified preventive public health action. The widespread occurrence and silent progression of atherosclerosis has created a cardiovascular diseases burden that is massive in terms of its attendant death and disability, as well as social and economic costs.

Atherosclerosis begins to develop in childhood and progresses into the adult years, significantly affected by the associated risk factors. Recent studies of children, adolescents, and young adults have demonstrated the close link of blood cholesterol level, blood pressure level, smoking, physical inactivity, and obesity with the extent and severity of atherosclerosis in the underage population. These findings underscore the opportunities for preventing cardiovascular diseases during childhood and adolescence, as well as the lifelong importance of prevention. In most children, atherosclerotic vascular changes are minor and can be minimized or even prevented with adherence to a healthy lifestyle. Accordingly, participation of children in sports and active play has never been more crucial than it is today. Furthermore, beside the beneficial role of physical activity in delaying or preventing metabolic complications, it has also been shown to improve bone mineral density, increase school performance, and have a positive effect on mental health.

\section{Introduction}

Due to their prevalence, the continuous increase in the number of patients, high mortality and disability rates, as well as social and economic costs, in the last decades cardiovascular diseases (CVDs) have attained an important place in the activities of the global public health policy makers. Atherosclerosis is at the core of the problem in the largest proportion of subjects with these diseases. According to the World Health Organization (WHO) data an estimated 17.5 million

\section{Sanja Kovacic ${ }^{1}$, Marko Sukreški² \\ 1 Department of Neurology, General Hospital Zabok and Hospital of Croatian Veterans, Zabok, Faculty of Medicine, University of Osijek, Croatia. \\ 2 Faculty of Kinesiology, University of Zagreb, Croatia.}

\section{Contact information:}

\section{Sanja Kovacic.}

Address: Dept. of Neurology. General Hospital Zabok and Hospital of Croatian Veterans. Bracak 8. 49210 Zabok, Croatia.

Tel: 00385912549404

Fax: 0038549204390

झ sanja.kovacic2@gmail.com

\section{Keywords}

Atherosclerosis; Cardiovascular Diseases; Risk Factors; Childhood Inactivity. 
people died from CVDs in 2012, representing 31\% of all global deaths. Of these deaths, an estimated 7.4 million were due to coronary heart disease and 6.7 million were due to stroke [1]. For all those reasons, under the leadership of the WHO all Member States (194 countries) agreed in 2013 on global mechanisms to reduce the avoidable noncommunicable diseases (NCD) burden, including a "Global action plan for the prevention and control of NCDs 2013-2020". This plan aims to reduce the number of premature deaths from NCDs by $25 \%$ by 2025 through nine voluntary global targets. All nine global targets directly or indirectly focus on preventing and controlling CVDs [2].

This review will discuss the evidence supporting the premise that lower physical activity in the industrialized world is associated with worse health outcomes as well as being an important independent risk factor for CVDs. A particular focus will be given to children's inactivity and, consequently, the future CVD burden for modern society .

\section{Methodology}

Relevant research concerning childhood inactivity and atherosclerosis was identified by searching the biomedical and social sciences databases for primary research material. A total of 6 research databases (ERIC - Educational Resources Information, Family \& Society Studies Worldwide, Ingenta, Medline, PreoceedingsFirst - OCLC, ScienceDirect and The Cochrane Library) were searched for publications from 1950 through to the present, with key articles obtained primarily from MEDLINE and The Cochrane Library.

In order to ensure that relevant studies were not missed, the search terms remained broad. These were "childhood inactivity", plus "atherosclerosis" anywhere in the title or abstract. No language restrictions were employed.

The searches produced a substantial amount of potentially relevant literature -321 full text reports were retrieved after screening 5451 titles and abstracts. After screening full reports, 72 met our inclusion criteria and were available within the relevant time frame. None of reviews cited duplicated the work described here.

\section{Pathogenesis of atherosclerosis}

Atherosclerosis is the process in which atherosclerotic plaques build up in the walls of the arteries causing their narrowing, hardening, and loss of elasticity [3]. It is a gradual process that begins in childhood, but clinically significant disease manifests in the mid-to-late decades of life $[4,5]$. Subclinical (asymptomatic) atherosclerosis is the most widespread pathology in humans.

More than a hundred years ago, in Saint Petersburg in 1913, Nikolai N. Anitschkow, a young Russian experimental pathologist who reported that simply feeding rabbits a high-cholesterol diet produced arterial lesions that closely resembled those of human atherosclerosis, proposed the key role of cholesterol in the pathogenesis of atherosclerosis [6]. Although the design of the experiment was subsequently criticized, the current understanding of cellular and molecular mechanisms of atherogenesis is still based on the classical lipid theory of atherosclerosis, postulating that the most important event in the development of atherosclerosis is the accumulation of extracellular and intracellular lipids in the arterial intima [7]. New research has established that atherosclerosis is characterized by a lipid-initiated chronic inflammation of vascular walls involving both innate and adaptive immune cells in the pathophysiologic process [8]. The major risk factors giving rise to atherosclerosis are elevated blood cholesterol, hypertension, smoking, obesity, diabetes, a sedentary lifestyle, and, of course, age because of the slow evolution of vascular inflammation [9]. So far, the elimination of risk factors is the most extensively studied area and is a widely used approach for the primary prevention of atherosclerosis [10]. Therefore, the accurate prediction 
of cardiovascular risk in asymptomatic individuals represents an important task of primary prevention medicine [11]. Recent public health activities in developed countries, resulting in increasingly intensive risk factor control, have contributed to significant reductions in the rates of atherosclerotic cardiovascular disease mortality. From 2001 to 2011, relative rates of coronary heart disease and stroke mortality in the United States declined by 30.8 and 35.1\%, respectively [12].

\section{Obesity in the light of evolution}

Visceral obesity (fat deposited in the abdominal region, particularly the viscera) was proven to result in greater systemic pathologic effects than other patterns of fat deposition [13]. It is considered to be strongly associated with the development of an array of metabolic disturbances including elevated blood pressure, dyslipidemia, impaired glucose tolerance or insulin resistance, prothrombotic state, and proinflammatory state, together referred to as the metabolic syndrome [14, 15]. In an article published in 1962, James Neel put forward a novel hypothesis to explain the growing incidence of diabetes mellitus in the mid-20th century human population [16]. The huge proportion of patients afflicted with diabetes and related metabolic disorders have prompted researchers to the idea of that these diseases would have hindered reproductive vitality and acted as a negative selection factor over the course of human evolution. To explain their persistence, Neel suggested that a "thrifty genotype," which modified the regulation of insulin release and glucose storage, may have provided a survival advantage for some of our hunter-gatherer predecessors [17]. Bellisari further elaborated this hypothesis in his review which revealed that primates have the capacity to store body fat when opportunities to consume excess energy arise [18]. Nevertheless, during most of primate evolution such opportunities were uncommon due to frequent starvation accompanied by high levels of physical activity. The evolution of encephalization in primates was supported by the coevolution of elaborate physiological systems to protect against starvation and defend stored body fat to provide for the metabolic needs of a large brain. Visceral fat was especially well constructed to resist lipolysis. With these biological mechanisms to maximize fuel efficiency in place, human primates went on to devise technological aids for increasing energy consumption and reducing physical effort. In the last century, industrialization provided not only access to great quantities of mass-produced, highcalorie foods, but also enabled a sedentary lifestyle, virtually abolishing starvation and heavy manual work in much of human society. In this modern obesogenic environment, individuals with the thriftiest combination of ancestral energy-conserving genes are at greatest risk for obesity.

\section{Sedentary lifestyle and cardiovascular risk}

Recent investigations have demonstrated that structured exercise programs or even moderate levels of physical activity suppress cardiovascular morbidity and mortality in the whole population $[19,20]$. Several cross-sectional studies independently correlated low exercise capacity with increased carotid intimamedia thickness (IMT) in both genders, which is of clinical importance $[21,22,23]$. Numerous scientific reports proved that vigorous physical activity is independently (e.g., without calorie restriction) inversely correlated with body fat and the prevalence of obesity [24, 25, 26, 27]. Carnethon's longitudinal studies reported a graded, inverse association of physical activity (PA) amount and duration (i.e., dose) with incident coronary heart disease (CHD) and stroke [28]. Furthermore, in the Health Professionals Follow-Up Study, PA "dose" was inversely associated with the incidence of CHD over time, with rates declining from 46.3, 39.3, 35.9, and 32.2 to 25.8 cases per 10000 person-years according to quintiles of activity [29]. A meta-analysis of 23 studies on the association of PA with stroke indicated that compared with low levels of activity, high (RR 
$0.79,95 \% \mathrm{Cl} 0.69-0.91)$ and moderate (RR 0.91, 95\% Cl 0.80-1.05) levels of activity were inversely associated with the likelihood of developing total stroke [30].

\section{Cardiovascular risk begins in childhood}

Although atherosclerosis is widely spread in the population, it can pass unnoticed for years. Autopsies have shown that atherosclerotic processes at the endothelial level begin in childhood and progress rapidly in the presence of risk factors [31]. The development of atherosclerosis is histopathologically visible first in the aorta. As described in the early fifties, it begins with the formation of a fatty streak. In childhood it is depicted as a reversible process [32]. In adolescence, some fatty streaks accumulate more lipids and begin to develop a fibromuscular cap, forming the lesion termed a fibrous plaque. In subsequent years, fibrous plaques enlarge and undergo calcification, hemorrhage, ulceration or rupture, and thrombosis. Thrombotic occlusion precipitates clinical disease, depending on which artery is affected [33]. In the Bogalusa Heart Study, histopathological atherosclerotic lesions were measured in arteries from 66 persons aged 6-30 years who were autopsied after death due to accidents, homicide, or suicide [34]. It was proven that LDL-cholesterol concentrations measured during life were positively associated with the percentage of surface involved by fatty streaks in the coronary arteries and aorta. Atherosclerosis risk increases with age, and unhealthy nutritional habits together with physical inactivity during childhood and adolescence have been suggested to favour atherosclerotic complications later in life [35, 36, 37]. It has been established that serum lipoprotein concentrations, smoking, obesity, and hyperglycemia are closely associated with fatty streaks in the second decade of life, while the same risk factors, along with hypertension, are associated with raised lesions in the third decade of life [38].

\section{Childhood obesity and inactivity}

In simple terms, obesity is the result of an energy imbalance, where the number of

calories expended is fewer than the number of calories taken in [39]. A recent study estimated that an excess energy of 110-165 kcal/day could be responsible for the increase in childhood obesity rates that was recorded when the 1988-1994 and the 1999-2002 NHANES data were compared [40]. Whereas the basic mechanism ("energy imbalance") can be simply described, the causes of the energy imbalance that affect food intake and energy expenditure are complex and span across many contexts including genetic, physiological, psychological, behavioural, sociocultural, and economic factors. Most researchers suggest that children today live in an "obesogenic" environment, where it is effortless to consume too many calories, while physical activity is discouraged [41, 42].

Recent epidemiological data suggest that the rate of severe obesity in adults and the prevalence of overweight in children are still on the rise, suggesting that the burden of obesity-related illnesses will continue to increase [13]. In the U.S., among children 2 to 19 years of age $31.7 \%$ are overweight and obese (which represents 23.6 million children), and $16.9 \%$ are obese (12.6 million children). Over the past 3 decades, the prevalence of obesity in children 6 to 11 years of age has increased from cca $4 \%$ to $>20 \%$ [43].

According to a report from the American Heart Association, the proportion of young people $(\leq 18$ years of age) who report engaging in no regular physical activity is high, and it increases with age. In 2009, among adolescents in grades 9 through $12,29.9 \%$ of girls and $17.0 \%$ of boys reported that they had not engaged in 60 minutes of moderateto-vigorous physical activity [43]. The proportion of children's inactivity varied by sex and race. The prevalence was highest in Afro-American (43.6\%) and Hispanic (30.5\%) girls, followed by Caucasian girls (25.4\%), Afro-American boys (20.6\%), Hispanic 
boys (17.4\%), and Caucasian boys (15.9\%) [44]. A study of Zimmermann-Sloutskis et al. that included 3068 youths between the ages of 14 and 24 years in the period from 1999 to 2006, found that the prevalence of inactivity went up with age in both boys and girls [45]. In a study of 12,812 youths aged 9 to 18 years, Kahn et al. revealed that physical activity levels in boys and girls declined starting at the age of 13 , with a significantly greater decline in activity among girls [46].

Looking at younger children, a national survey of 9-13-year olds in 2002 (Youth Media Campaign Longitudinal Survey) found that, although lacking reference to the intensity of physical activity, almost one-quarter $(22.6 \%)$ of the children did not engage in any free-time physical activity [47]. The Middle School YRBS, modeled on the High School YRBS and conducted in a number of states and cities among middle school students in 2003 [48], showed that across cities, the median percentage of students in the $6^{\text {th }}, 7^{\text {th }}$, and $8^{\text {th }}$ grades who did not participate in physical activities that made them sweat and breathe hard for 20 minutes or more on at least 3 of the 7 days preceding the survey, ranged from $34.7 \%$ to $42.7 \%$. This illustrates the fact that a large percentage of middle school students are not engaging in vigorous physical activity. A more recent study of physical activity in 10-16-year olds used an objective measure of physical activity (i.e., motion detectors), rather than the usual selfor-parent-reported measures. The results showed that these children spend an average of only 12.6 minutes per day engaged in vigorous physical activity [49]. The most current YRBSS (2005) among high school students revealed that 64.2 percent of students did not meet the current recommended levels of physical activity (doing any kind of physical activity that increased their heart rate and made them breathe hard some of the time for a total of at least 60 minutes/day on 5 or more of the 7 days preceding the survey) [50]. As often found, girls were less active than boys; $56.2 \%$ of male high school students failed to meet these recommendations for physical activity, as compared with almost three-quarters (72.2\%) of female students [50].

While data on general physical activity trends show that inadequate physical activity levels have remained unchanged and we have seen no improvement since 1991 [51], it clearly appears that the percentage of students who walk or bike to and from school has declined substantially over the past 35 years. It has been reported that while $48 \%$ of students walked or biked to school in 1969, only $15 \%$ walked and 1\% biked in 2001 [52]. The percentages of walkers and bikers are higher for those who live within 1 to 2 miles of school [52, 53], but the numbers still represent a significant decline from a few decades ago. According to a 1999 Healthy Styles Survey, among participating households, $25 \%$ of children aged 5 to 15 years who lived within a mile of school had either walked or bicycled at least once during the month before the survey [54]. These numbers should be contrasted with the numbers from 1969, where the figure was close to $90 \%$ [55].

Time spent in sedentary activity is time not engaged in more active pursuits, and therefore may reduce the opportunity for children to be outdoors and be physically active [56]. Estimates vary, but it appears that many children and adolescents exceed the recommended limit of 2 hours of television watching per day. Recent national data among high school students report that $38 \%$ of high school students watched three or more hours of television on a typical school day [50], which is only a slight decrease from the $42.8 \%$ in 1999 [57]. Data on television viewing among children aged 3 to 12 years show a decline by approximately 4 hours/ week between 1981 and 1997 [56]. Among older children (8th, 10th, and 12th graders), heavy television watching (4 hours or more) in 2004 was slightly lower than it was in 1991, with the rates fluctuating between those years [58]. On the other hand, television viewing for one hour or less has 
increased [58]. However, these trends in television viewing alone do not provide a complete picture of children's sedentary behaviours. Children today may substitute some time previously spent on television viewing with other sedentary activities such as personal computer use for exchanging emails or visiting websites and playing video games. In fact, data show that in addition to television viewing, other sedentary pursuits may contribute to the physical inactivity of today's youth. For example, heavy computer use of 3 or more hours per day on an average school day, playing video or computer games, or using the computer for recreation was reported by $21.1 \%$ of high school students in 2005 [50]. A more comprehensive look at the sedentary behaviours among children including various media use is available from a Kaiser Family Foundation survey released in 2005 [59]. Among 8-18-year olds, it was found that the amount of non-school related use of media (including TV, DVDs, videos, video games, computer use, movies, music, and print) has increased by over an hour during the past five years, from about 7.5 hours to 8.5 hours a day. The increases were most evident in computer use and video games. However, since multitasking of media has increased as well, the actual number of media use hours has shown little change at about 6.5 hours a day ( 44.5 hours a week). This amount of time is interpreted as more than the equivalent of a full-time job across the seven days of the week. Among the 6.5 hours a day of media time, the average amount of time spent watching TV/DVDs/ videos in this group averaged almost four hours per day [59]. Even younger children aged 2-7 years were reported to spend close to 4.5 hours a day using media in 1999 [60]. Considering uses of different media at the same time, the total amount of time actually spent on media use was about 3.5 hours a day [60]. Screen media use (mostly TV and videos) by children six and under, reported by their parents in 2003, indicated an average of about 2 hours a day, which was about the same amount of time that the children spent playing outside [60]. In spite of the recommendation by the American Academy of Pediatrics that children under two should not watch any television, $68 \%$ of children under two used screen media including TV, video, or DVD, for an average of about 2 hours per day. A study using objective measures of physical activity showed that 10-16-year olds spent an average of 10.4 hours a day relatively motionless. They spent an average of a little over five hours per day doing homework, sitting at the computer, or watching television. The remaining sedentary time was spent mainly at school [49]. Sedentary behaviours resulting from the advanced engineering of everyday objects such as use of remote control devices and elevators/escalators must have reduced "unconscious" exercise among children and adolescents. However, we do not have information concerning shifts in children's energy expenditure as a result of the changes in everyday functioning to document such trends. In summary, data on media use demonstrate that children today are spending far too much time engaging in many sedentary activities, such as watching TV, playing video games, and using computers. The rise in computers and other sedentary leisure pursuits over the past twenty years offers a list of attractive opportunities for spending time during which children and adolescents are sedentary, while similarly appealing new outlets for physical activity have not followed that trend.

\section{Benefits of physical activity in children}

Regular physical activity is crucial for health and well-being [61]. Physical activity in

children, structured or unstructured free play, is essential to maintaining an energy balance, promoting a healthy weight, and supporting cognitive, physical, social, and emotional development and well-being [62, 63]. Boreham and Riddoch [64] describe the three main health benefits that come from adequate childhood activity as: (a) the direct improvement of childhood health status and quality 
of life; (b) the direct improvement of future adult health status by preventing or delaying the onset of many chronic diseases, and (c) an increased likelihood of maintaining an active lifestyle as an adult. Health benefits of physical activity in adults include: a healthy weight; the prevention of high blood pressure, high cholesterol, type 2 diabetes, and heart disease; a reduced risk of osteoporosis and certain types of cancers; increased muscle strength and endurance; and healthy joints. Physical activity also helps reduce feelings of depression and anxiety, and assists with mood management $[61,65,66]$.

A review of the literature has found evidence that active children have healthier cardiovascular profiles than non-active children [64]. There is evidence of a relationship between physical activity and lipid and lipoprotein levels in adolescents $[39,64,67]$. In addition, there is evidence to suggest that physical activity in childhood or adolescence can prevent or delay the development of high blood pressure later in life $[66,69]$. Physical activity may also lower blood pressure in hypertensive adolescents [65, 68, 69]. A recent study found that physical activity was inversely associated with levels of fasting insulin, glucose, and triglycerides among children aged 9-10 and 1516 [70]. It has also been found that physical activity in children and adolescents can help increase peak bone mass, and thus reduce the risk of adult osteoporosis [64, 65]. Levels of physical activity also seem to be associated with physical fitness. In a representative sample of 12 to 19-year olds, cardiorespiratory fitness was likely to be lower among youths with low levels of physical activity and high levels of sedentary behaviour [71].

\section{Strategies for improved cardiovascular health in the future}

In the context of growing childhood inactivity, the National Association for Sport and Physical Education recommend that children aged 5 through 12 accumulate a minimum of 60 minutes of activity each day and avoid long periods of inactivity, whi- le the Physical Education Guidelines recommend that 150 minutes of instructional physical education each week should be provided by elementary schools, and 225 minutes weekly by middle and high schools [72].

Realizing the importance of the issue of children's inactivity, WHO has instituted a policy option intended to advance the implementation of a global strategy on diet and physical activity with the voluntary global target of a $10 \%$ relative reduction in the prevalence of insufficient physical activity, which should halt the rise in diabetes and obesity. The proposed policy, among other options, includes the creation and preservation of built and natural environments which support physical activity in schools, universities, workplaces, clinics and hospitals, and in the wider community, with a particular focus on providing infrastructure to support active transport, i.e., walking and cycling, active recreation and play, and participation in sports (2). Taken together, these data continue to indicate the substantial progress that will need to occur for the WHO to achieve its 2020 Impact Goals over this decade. If the goals can be met, there is evidence suggesting that CVD event rates could decrease significantly.

\section{Conclusions}

Long-range prevention of CVDs should begin in childhood with control of the risk factors to limit the extent of juvenile vascular fatty streaks and, more critically, to prevent or retard their progression to

raised lesions. To achieve improvements in cardiovascular health of future generations, all segments of the population will need to focus on improved cardiovascular health behaviours of children, in particular with regard to an increase in physical activity, as well as on diet and weight. Increasingly important objectives for developed and especially for developing countries should include increasing the numbers of individuals who do not smoke, who eat healthy diets, and who are physically active at levels 
that are health enhancing. More children, adolescents, and young adults will need to learn how to preserve their ideal levels of cardiovascular health factors and health behaviours into old age.

\section{Acknowledgements}

No

\section{Potential conflicts of interest}

No

\section{References}

1. World Health Organisation. Global Status Report on Noncummunicable Disease. WHO Press: Geneva 2014.

2. World Health Organisation. Global Action Plan for the Prevention and Control of Noncommunicable Diseases. 2013-2020. WHO Press: Geneva 2013.

3. Thubrikar MJ. Vascular Mechanics and Pathology. Berlin: Springer Science; 2007.

4. McGill HC Jr., McMahan CA. Determinants of atherosclerosis in the young. Pathobiological determinants of atherosclerosis in youth (PDAY) research group. Am J Cardiol 1998; 82: 30-36.

5. Tuzcu EM, Kapadia SR, Tutar E, Ziada KM, Hobbs RE, McCarthy PM et al. High prevalence of coronary atherosclerosis in asymptomatic teenagers and young adults: evidence from intravascular ultrasound. Circulation 2001; 103: 2705-2710.

6. Steinberg D. In celebration of the 100th anniversary of the lipid hypothesis of atherosclerosis. J Lipid Res 2013; 54: 2946-2949.

7. Konstantinov IE, Mejevoi N, Anichkov NM, Nikolai N. Anichkov and his theory of atherosclerosis. Tex Heart Inst J 2006; 33: 417423.

8. Hamze M, Desmetz C, Berthe ML, Roger P, Boulle N, Brancherau $P$ et al. Characterization of resident $B$ cells of vascular walls in human atherosclerotic patients. J Immunol 2013; 191: 30063016.

9. McGill HC, McMahan CA, Gidding SS. Preventing heart disease in the 21st century: implications of the pathobiological determinants of atherosclerosis in youth (PDAY) study." Circulation 2008; 117: 1216-1227.

10. Fowkes FGR, Rudan D, Rudan I, Aboyans V, Denenberg JO, McDermott $\mathrm{MM}$ et al. Comparison of global estimates of prevalence and risk factors for peripheral artery disease in 2000 and 2010: a systematic review and analysis. Lancet. 2013; 382: 1329-1340.
11. Goff DC Jr, Lloyd-Jones DM, Bennett G, Coady S, D'Agostino R, Sr, Gibbsons R et al. 2013 ACC/AHA guideline on the assessment of cardiovascular risk: a report of the American College of Cardiology/American Heart Association task force on practice guidelines. Circulation 2014; 129: S49-S73.

12. Mozaffarian D, Benjamin EJ, Go AS, Arnett DK, Blaha MJ, Cushman $\mathrm{M}$ et al. Heart disease and stroke statistics-2015 update: a report from the American Heart Association. Circulation 2015; 131: e29-e322.

13. Bessesen DH. Update on obesity. J Clin Endocrinol Metab 2008; 93: 2027-2034.

14. Shively CA, Register TC, Clarkson TB. Social stress, visceral obesity, and coronary artery atherosclerosis: product of a primate adaptation. Am J Primatol 2009; 71: 742-751.

15. Despres JP, Lemieux I. Abdominal obesity and metabolic syndrome. Nature 2006; 444: 881-887.

16. Neel JV. Diabetes Mellitus: A, thrifty genotype rendered detrimental by "progress". Am J Hum Genet 1962; 14: 353-62.

17. Chakravarthy MV, Booth FW. Eating, exercise, and "thrifty" genotypes: connecting the dots toward an evolutionary understanding of modern chronic diseases. J Appl Psychol 2004; 96: 3-10.

18. Bellisari A. Evolutionary origins of obesity. Obes Rev 2008; 9:165-180.

19. $\mathrm{NIH}$ consensus development panel on physical activity and cardiovascular health. Physical activity and cardiovascular health. J Amer Med Assoc 1996; 276: 241-246.

20. Kadoglou NPE. Exercise and carotid atherosclerosis. Eur J Vasc Endovasc Surg 2008; 35: 264-272.

21. Tanaka H, Seals DR, Monahan KD, Clevenger CM, DeSouza CA, Dinenno FA. Regular aerobic exercise and the age-related increase in carotid artery intima-media thickness in healthy men." J Appl Physiol 2002; 92: 1458-1464.

22. Hagg U, Wandt B, Bergstrom G, Volkmann R, Gan LM. Physical exercise capacity is associated with coronary and peripheral vascular function in healthy young adults. J Appl Physiol 2005; 289: 1627-1634.

23. Moreau KL, Donato AJ, Seals DR, Dinenno FA, Blackett SD, Hoetzer GL et al. Arterial Intima-media thickness: site-specific associations with HRT and habitual exercise. Am J Physiol-Heart C 2002; 283: 1409-1417.

24. Kim Y, Lee S. Physical activity and abdominal obesity in youth. Appl Physiol Nutr Metab 2009; 34: 571-581.

25. Barbeau P, Johnson MH, Howe CA, Allison J, Davis CL, Gutin $B$ et al. Ten months of exercise improves general and visceral adiposity, bone, and fitness in black girls. Obesity 2007; 15: 2077-2085.

26. Bell LM, Watts K, Siafarikas A, Thompson A, Ratnam N, Bulsara $M$ et al. Exercise alone reduces insulin resistance in obese children independently of changes in body composition. J Clin Endocrinol Metab 2007; 92: 4230-4235. 
27. Benson AC, Torode ME, Fiatarone Singh MA. The effect of highintensity progressive resistance training on adiposity in children: a randomized controlled trial. Int J Obes 2008; 32: 1016-1027.

28. Carnethon MR. Physical activity and cardiovascular disease: how much is enough? Am J Lifestyle Med Suppl 2009; 3: 44S-49S.

29. Tanasescu M, Leitzmann MF, Rimm EB, Willett WC, Stampfer $\mathrm{MJ}, \mathrm{Hu} \mathrm{FB}$. Exercise type and intensity in relation to coronary heart disease in men. J Am Med Assoc 2002; 288: 1994-2000.

30. Lee CD, Folsom AR, Blair SN. Physical activity and stroke risk: a meta-analysis. Stroke 2003; 34: 2475-2481.

31. Krishnan P, Balamurugan A, Urbina E, Srinivasan SR, Bond $\mathrm{G}$, Tang $\mathrm{R}$ et al. Cardiovascular risk profile of asymptomatic healthy young adults with increased carotid artery intima-media thickness: the Bogalusa Heart Study. J La State Med Soc 2003; 155: 165-169.

32. Duff GL, McMillan GC. Pathology of atherosclerosis. Am J Med 1951; 1: 92-108

33. McGill HC Jr., Geer JC, Strong JP. Natural history of human atherosclerotic lesions. In: Sandler M, Bourne GH, editors. Atherosclerosis and its Origin. New York: Academic Press; 1963. p. 39-65.

34. Berenson GS, Wattigney WA, Tracy RE, Newman WP, Srinivasan SR, Webber LS et al. Atherosclerosis of the aorta and coronary arteries and cardiovascular risk factors in persons aged 6 to 30 years and studied at necropsy: the Bogalusa Heart Study. Am J Cardiol 1992; 70: 851-8.

35. Reddick RL, Zhang SH, Maeda N. Aortic atherosclerotic plaque injury in apolipoprotein E deficient mice. Atherosclerosis 1998; 140: 297-305

36. Mahe G, Carsin M, Zeeny M, De Bosschere JP. Dietary pattern, a modifiable risk factor that can be easily assessed for atherosclerosis vascular disease prevention in clinical practice. Public Health Nutr 2011; 14: 319-26.

37. Myers J, McAuley J, Lavie CJ, Despress J-P, Arena R, Kokkinos P. Physical activity and cardiorespiratory fitness as major markers of cardiovascular risk: their independent and interwoven importance to health status. Prog Cardiovasc Dis 2015; 57: 306314

38. McGill HC Jr., McMahan CA, Herderick EE, Malcom GT, Tracy RE, Strong JP. Origin of atherosclerosis in childhood and adolescence. Am J Clin Nutr Suppl 2000; 72: 1307S-15S.

39. Koplan JP, Liverman CT, Kraak VA. Preventing Childhood Obesity: Health in the Balance. Washington DC: National Academies Press; 2005.

40. Wang YC, Gortmaker SL, Sobol AM, Kuntz KM. Estimating the energy gap among US children: a counterfactual approach. Pediatrics 2006; 118: e1721-1733.

41. Stanton RA. Nutrition problems in an obesogenic environment. Med J Aust 2006; 184: 76-79.

42. Carter MA, Swinburn B. Measuring the "obesogenic" food environment in New Zealand primary schools. Health Promot Int 2004; 19: 15-20.
43. Roger VL, Go AS, Lloyd-Jones DM, Benjamin EJ, Berry JD, Borden WB et al. Heart disease and stroke statistics--2012 update: A report from the American Heart Association. Circulation 2012; 125: e2-e220.

44. Eaton DK, Kann L, Kinchen S, Shanklin S, Ross J, Hawkins J et al. Centers for Disease Control and Prevention (CDC). Youth risk behavior surveillance - United States. MMWR 2010; 59: 1-142.

45. Zimmermann-Sloutskis D, Wanner, M, Zimmermann E, Martin BW. Physical activity levels and determinants of change in young adults: a longitudinal panel study. Int J Behav Nutr Phys 2010; 7: 2.

46. Kahn JA, Huang B, Gillman MW, Field AE, Austin SB, Colditz GA et al. Patterns and determinants of physical activity in U.S. adolescents. J Adolesc Health 2008; 42: 369-377.

47. Centers for Disease Control and Prevention. Physical activity levels among children aged 9-13 years - United States. MMWR 2002; 52: 785-788.

48. Whalen, LG, Grunbaum, JA, Kinchen, S, McManus, T, Shanklin, S, Kann, L (2006). Middle school youth risk behavior survey 2003: U.S. Department of Health and Human Services, Centers for Disease Control and Prevention. [WWW document]. URL http://www.cdc.gov/healthyyouth/yrbs/middleschool

49. Strauss RS, Rodzilsky D, Burack G, Colin, M. Psychosocial correlates of physical activity in healthy children. Arch Pediatr Adolesc Med 2001; 155: 897-902.

50. Eaton DK, Kann L, Kinchen S, Ross J, Hawkins J, Lowry R et al. Youth risk behavior surveillance - United States. MMWR 2006; 55: 1-108.

51. Wang G, Dietz WH. Economic burden of obesity in youths aged 6 to 17 years: 1979-1999. Pediatrics 2002; 109: E81-81.

52. Environmental Protection Agency. Travel and Environmental Implications of School Sitting. Washington, D.C.: U.S. Environmental Protection Agency; 2003. EPA 231-R-03- 004.

53. Epstein LH, Paluch RA, Coleman KJ, Vito D, Anderson K. Determinants of physical activity in obese children assessed by accelerometer and self-report. Med Sci Sports Exerc 1996; 28 : $1157-1164$

54. Centers for Disease Control and Prevention. Barriers to children walking and biking to school - United States. MMWR 2002; 51 : 701-704.

55. Nationwide Personal Transportation Study. Transportation Characteristics of School Children, Report No. 4. 1972. Washington, DC: Federal Highway Administration.

56. Kohl HW 3rd, Hobbs KE. Development of physical activity behaviors among children and adolescents. Pediatrics 1998; 101: 49-554

57. Kann L, Kinchen SA., Williams BI, Ross JG, Lowry R, Grunbaum JA et al. Youth risk behavior surveillance - United States, 1999. MMWR 2000; 49: 1-32. 
58. Child Trends. Watching Television. [WWW document]. URL http://www.childtrendsdatabank.org/pdf/55 PDF.pdf.

59. Rideout VJ, Roberts DF, Foehr UG. Generation M: Media in the Lives of 8-18 Year Olds. Henry J. Kaiser Family Foundation: Menlo Park, CA 2005.

60. Roberts DF, Foehr UG, Rideout VJ, Brodie M. Kids \& Media @ the New Millennium. Henry J. Kaiser Family Foundation: Menlo Park, CA 1999

61. U.S. Department of Health and Human Services (DHHS). Physical Activity Fundamental to Preventing Disease. 2002.

62. Ginsburg KR. The importance of play in promoting healthy child development and maintaining strong parent-child bonds. Pediatrics 2007; 119: 182-191.

63. Burdette HL, Whitaker RC. Resurrecting free play in young children: looking beyond fitness and fatness to attention, affiliation, and affect. Arch Pediatr Adolesc Med 2005; 159: 4650.

64. Boreham C, Riddoch C. The physical activity, fitness and health of children. J Sports Sci 2001; 19: 915-929.

65. U.S. Department of Health and Human Services (DHHS). Physical Activity and Health: A Report of the Surgeon General. GA: CDC: Atlanta 1996

66. Sothern MS, Loftin M, Suskind RM, Udall JN, Blecker U. The health benefits of physical activity in children and adolescents: implications for chronic disease prevention. Eur J Pediatr 1999; 158: 271-274.

67. Armstrong N, Simons-Morton B. Physical activity and blood lipids in adolescents. Pediatr Exer Sci 1994; 6: 381-405.

68. Secretary of Health and Human Services, Secretary of Education, (2000). Promoting Better Health for Young People Through Physical Activity and Sports. [WWW document]. URL https:// www2.ed.gov/offices/OSDFS/physedapndc.pdf 2000.

69. Alpert BS, Wilmore JH. Physical activity and blood pressure in adolescents. Pediatr Exer Sci 1994; 6: 361-380.

70. Ekelund U, Brage S, Froberg K, Harro M, Anderssen SA, Sandirha LB et al. TV viewing and physical activity are independently associated with metabolic risk in children: the European youth heart study. PLoS Med 2006; 3: e488.

71. Pate RR, Wang CY, Dowda M, Farrell SW, O'Neill JR. Cardiorespiratory fitness levels among US youth 12 to 19 years of age: findings from the 1999-2002 National health and nutrition examination survey. Arch Pediatr Adolesc Med 2006; 160: 1005-1012.

72. National Guidelines. National Association for Sport and Physical Education, (2011). [WWW document]. URL http://WwW. aahperd.org/naspe/standards/nationalGuidelines/
Publish in International Archives of Medicine

International Archives of Medicine is an open access journal publishing articles encompassing all aspects of medical science and clinical practice. IAM is considered a megajournal with independent sections on all areas of medicine. IAM is a really international journal with authors and board members from all around the world. The journal is widely indexed and classified Q1 in category Medicine. 